\title{
O ENSINO DO CONCEITO DE FRAÇÃO NO ENSINO FUNDAMENTAL: UMA PROPOSTA DE ATIVIDADE
}

\author{
Thaís de Souza Machado'; Luis Sebastião Barbosa Bemme ${ }^{2}$
}

\section{RESUMO}

Nessa comunicação temos por objetivo apresentar uma proposta de atividade para o ensino do conceito de fração no sexto ano do Ensino Fundamental. Tal atividade tem como base a proposta teórica e metodológica da Atividade Orientadora de Ensino. Para isto, elaborou-se uma sequência de atividades com objetivos específicos de forma a contemplar os momentos definidos na Atividade Orientadora de Ensino. Como resultados e conclusões, apostamos nessa metodologia por acreditar que podemos construir inúmeros meios no ensino, de modo a pôr o aluno como o foco principal da aprendizagem, possibilitando sua protagonização, autonomia e criatividade.

Palavras-chave: Ensino de Matemática; Situação Desencadeadora de Ensino; Anos Finais.

Eixo Temático: Educação, Cultura e Comunicação (ECC).

\section{INTRODUÇÃO}

Nesta comunicação, apresentamos uma proposta de atividade para o ensino do conceito de fração no sexto ano do Ensino Fundamental.

A justificativa pela escolha do conteúdo de fração tem como base o fato de que esse conceito é fundamental para a construção da própria matemática além de ter uma grande aplicabilidade cotidiana. A motivação para este estudo partiu do reconhecimento, pela autora, de que nesse conceito se encontraram muitas dificuldades durante sua aprendizagem e faz-se necessário pensar em metodologias que possibilitem uma melhor compreensão do mesmo.

A primeira ação desenvolvida foi o estudo teórico da Base Nacional Comum Curricular - BNCC (BRASIL, 2017), que indica que as ações de ensino sobre o conceito de fração devem visar o desenvolvimento de habilidades como compreender,

\footnotetext{
1 Autora. Universidade Franciscana. E-mail: thais.souza@ufn.edu.br.

2 Orientador. Universidade Franciscana. E-mail: luis.sebastião@ufn.edu.br
} 
comparar e ordenar frações, além de resolver e elaborar problemas que envolvam o cálculo da fração de uma quantidade.

Para contemplar estas habilidades, optou-se pela metodologia de Atividade Orientadora de Ensino - AOE (MOURA, 1996). Esta metodologia possibilita o resgate do movimento lógico-histórico do conceito, o que favorece a compreensão para além dos algoritmos, regras e procedimentos. Essa metodologia pode ser empregada para a introdução ou retomada de um conceito já trabalhado.

Segundo Moura (2002), "tomar o ensino como uma atividade implica em definir o que se busca concretizar com ela, isto é, a atividade educativa tem por finalidade aproximar os sujeitos de um determinado conhecimento" (p. 157).

Neste sentido, a Atividade Orientadora de Ensino - AOE, vem como uma possibilidade para facilitar a aquisição dos conhecimentos científicos, a partir de um resgate de conhecimentos historicamente construídos. Para isto, o planejamento do professor deve ser organizado de maneira que possibilite aos estudantes a apropriação dos conhecimentos historicamente elaborados pela humanidade (MOURA et al., 2010, p. 218).

Desta forma, apontamos como uma possibilidade para a organização do ensino a AOE, já que ela proporciona que o aluno se aproprie de conhecimentos a partir da necessidade de tê-los, vivenciando de modo semelhante a necessidade que se teve no passado para a construção do conceito em questão.

Evidencia-se na AOE o trabalho em grupo, visto que essa forma permite que os alunos discutam, argumentem e reflitam métodos de resolução, tanto do seu grupo quanto do outro. Sendo assim, essa metodologia requer uma organização de modo que a atividade se caracterize como uma atividade orientadora. Destacamos três momentos dessa proposta: a Síntese Histórica do Conceito, a Situação Desencadeadora de Aprendizagem e a Síntese da Solução Coletiva.

O primeiro momento compreende a Síntese Histórica do Conceito. Neste momento está centrado no professor, é preciso que ele identifique qual foi o movimento lógico-histórico que gerou este conceito.

Para o segundo momento temos a criação da Situação Desencadeadora de Aprendizagem - SDA, é nela que a Síntese Histórica do Conceito deve estar presente, 
pois segundo Moura et al. (2010), esse modo tem por objetivo "proporcionar a necessidade de apropriação do conceito pelo estudante, de modo que suas ações sejam realizadas na busca da solução de um problema que o mobilize para atividade de aprendizagem" (p. 221).

Para expor a SDA aos estudantes, o professor pode recorrer a diversas metodologias, como jogos, situações cotidianas e a história virtual, compreendida como uma narrativa criada pelo professor, observando que nesses enredos deve haver a situação desencadeadora de modo que gere no aluno a mesma necessidade semelhante a vivida pelo homem no passado.

O terceiro e último momento observado é a Síntese da Solução Coletiva, vindo como a oportunidade de os alunos apresentarem as soluções encontradas para a atividade proposta. Salienta-se que a solução, feita de modo coletivo, deve ir ao encontro com a solução matematicamente correta para o problema, devendo o professor mediar essa trajetória com dicas do que se pode fazer.

$\mathrm{Na}$ apresentação da Síntese da Solução Coletiva, o professor terá a possibilidade de analisar até que ponto os alunos compreenderam o problema proposto. O mais importante neste momento não é o professor dar as respostas, mas fazer as perguntas corretas de modo que gere reflexões nos alunos e que eles por si mesmos sejam capazes de verificar a coerência entre as respostas dadas e o problema proposto.

Tal metodologia tem como aporte teórico a Teoria Histórico-Cultural de Vygotsky. Na concepção teórica que assumimos, o professor é entendido como um agente mediador entre os conhecimentos historicamente elaborado, uma vez que, segundo Vygotsky (2005), o processo de aquisição de conhecimentos nunca se dá de forma direta e isolada, mas fundamentalmente em uma relação mediada entre signos, instrumentos e nas relações sociais.

Vygotsky (2005) salienta que, durante o processo de desenvolvimento humano, há dois níveis distintos, sendo eles o Nível de Desenvolvimento Real e o Nível de Desenvolvimento Potencial. O nível de desenvolvimento real trata-se das ações que os alunos conseguem desenvolver de forma independente, ou seja, não necessitam 
do auxílio de alguém, e o nível de desenvolvimento potencial diz a respeito das ações que os alunos precisam de um auxílio de outro sujeito.

Então, percebe-se que há uma distância entre esses dois níveis de desenvolvimento, visto que em um o aluno é totalmente independente e no outro ele necessita de um apoio de alguma pessoa para realizar sua ação. Vygotsky denomina essa distância como Zona de Desenvolvimento Proximal - ZDP (VYGOTSKY, 2002). Pensar nesses níveis e na educação humanizadora, faz com que estimule o professor a refletir suas metodologias empregadas e pensar em quais outras podem surgir como possibilidade para o ensino, visto que essa educação deve resgatar os conhecimentos historicamente construídos e aproveitar o máximo do desenvolvimento do aluno.

\section{METODOLOGIA}

Este projeto alia-se a uma abordagem qualitativa, pois buscamos compreender, com base em dados qualificáveis, a realidade de determinados fenômenos, a partir da percepção dos diversos atores sociais (GIL, 1999; CERVO; BERVIAN, 2002). Quando denominados como "atores sociais", neste projeto, entende-se pelos alunos que farão parte desta pesquisa, e para contemplar os aspectos dessa abordagem, estes serão direcionados a refletir suas ações durante o processo de aprendizagem de frações.

Essas atividades foram elaboradas durante a disciplina de Trabalho Final de Graduação I - TFG, fazendo parte do projeto de TFG e após se ter as análises dos dados da aplicação obtidos, integrará o Trabalho Final de Graduação II, sendo este parte essencial para a conclusão do curso de Matemática da Universidade Franciscana.

\section{RESULTADOS E DISCUSSÕES}

Neste trabalho a Atividade Orientadora de Ensino - AOE, foi dividida em momentos distintos, juntamente com o objetivo, que são apresentados no quadro 01 .

Quadro 01 - Momentos, ações e objetivos da AOE

\begin{tabular}{|l|l|l|}
\hline Momento & Ações & Objetivo \\
\hline
\end{tabular}




\begin{tabular}{|c|c|c|}
\hline $\begin{array}{l}\text { EDUCAÇÃO, SAÚDE } \\
\text { E TECNOLLGIA } \\
26 \text { A } 28 \text { DE OUTUBRO DE } 2021\end{array}$ & & $\begin{array}{r}\text { ISSN: } 2316-9745 \\
\text { TRABALHO COMPLETO }\end{array}$ \\
\hline $\begin{array}{l}\text { Situação } \\
\text { Desencadeadora } \\
\text { Aprendizagem - SDA }\end{array}$ & $\begin{array}{l}\text { Inicialmente a turma será } \\
\text { dividida em grupos, após } \\
\text { era entregue a SDA e os } \\
\text { demais materiais } \\
\text { manipuláveis. Será pedido } \\
\text { que leiam individualmente } \\
\text { e depois será lido com o } \\
\text { grande grupo. } \\
\text { Será iniciado a síntese por } \\
\text { parte dos grupos. }\end{array}$ & $\begin{array}{l}\text { i. Ler e interpretar a } \\
\text { situação desencadeadora } \\
\text { de aprendizagem; } \\
\text { ii. Refletir sobre as } \\
\text { possibilidades de } \\
\text { resolução da situação } \\
\text { desencadeadora de } \\
\text { aprendizagem. }\end{array}$ \\
\hline Síntese Coletiva & $\begin{array}{l}\text { Após concluírem suas } \\
\text { sínteses, cada grupo irá } \\
\text { escrever a síntese em } \\
\text { uma cartolina } \\
\text { apresentar para a turma. } \\
\text { Após as apresentações, } \\
\text { será discutido as sínteses } \\
\text { e reescritas, na linguagem } \\
\text { matemática, a síntese } \\
\text { correta. }\end{array}$ & $\begin{array}{l}\text { i. Apresentar e discutir as } \\
\text { sínteses da SDA de cada } \\
\text { grupo de alunos; } \\
\text { ii. Construir uma síntese } \\
\text { única, e matematicamente } \\
\text { correta, para a SDA. }\end{array}$ \\
\hline Síntese do Conceito & $\begin{array}{l}\text { Terminado a parte inicial } \\
\text { da SDA, será feito uma } \\
\text { retomada geral do } \\
\text { conteúdo de frações } \\
\text { (elementos da fração e } \\
\text { operações), dando } \\
\text { aportes para a realização } \\
\text { de uma avaliação, que } \\
\text { será o fechamento da } \\
\text { atividade. }\end{array}$ & $\begin{array}{l}\text { i. Retomar o conceito de } \\
\text { frações. }\end{array}$ \\
\hline
\end{tabular}

Fonte: Autora 
A primeira aula, está dentro do primeiro momento, trata-se da Situação Desencadeadora de Aprendizagem - SDA. Neste momento, será separada a turma em pequenos grupos e entregue para cada aluno uma impressão da situação que eles devem analisar e dos demais materiais manipuláveis para eles conseguirem ter uma noção do que a situação se trata. Essa primeira aula, fica reservada para que os grupos elaborem suas sínteses individuais.

$\mathrm{Na}$ segunda aula, classificada no segundo momento, será entregue uma cartolina e um canetão, para cada grupo, a fim de que escrevam as sínteses que eles encontraram e que posteriormente façam a apresentação dela. Na terceira aula será a apresentação das sínteses dos grupos e um debate com toda a turma das sínteses encontradas, para que se caso houver sínteses diferentes, poder chegar a um consenso.

$\mathrm{Na}$ quarta aula, onde compreende o terceiro momento, será apresentada a síntese, matematicamente, correta da SDA, e uma retomada geral do conteúdo de frações para que os alunos tirem suas dúvidas, quanto ao conteúdo, e possam realizar uma avaliação na aula seguinte. Na quinta e última aula, será realizada uma avaliação sobre o conteúdo trabalhado de frações, a fim de se conhecer o que os conhecimentos adquiridos pelos alunos, tanto no conteúdo quanto na $\mathrm{AOE}$.

Espera-se que as aulas ocorram de maneira tranquila, obedecendo o tempo dos alunos de análise, reflexão e desenvolvimento da situação desencadeadora de aprendizagem.

\section{CONCLUSÃO}

Ao se estudar os referenciais teóricos aqui apresentados, percebe-se que o ensino de frações estagnou na mera apresentação da forma fracionária e de imagens divididas para que o aluno reconheça que fração representa. É notório que no primeiro contato do aluno com esse conteúdo seja necessária essa metodologia, porém trabalhar com algo concreto, em que os alunos possam manipular, torna o ensino mais fácil, tanto visualmente quanto mentalmente.

Muitas vezes, a opção por utilizar as mesmas metodologias vem do conforto que os professores sentem, por saber que daquela forma eles conseguem passar 0 
conteúdo e que irá alcançar boa parte de sua turma. Percebe-se, também, que os professores têm medo de se arriscarem em novos métodos de ensino por, ou não se garantirem na aplicação ou por medo de os alunos não se identificarem e acabarem por não conseguirem aprender.

Dessa forma, evidenciamos a Atividade Orientadora de Ensino - AOE, pelo fato dela permitir que o aluno construa sua rede de raciocínio e que sinta a necessidade de se apropriar do conhecimento que precisa para resolver determinada situação. Essa metodologia torna o aluno um agente ativo em sua aprendizagem, possibilitando a construção do gosto pelos estudos, já que serão eles que irão estar no centro do conteúdo, não mais sendo o professor como um transmissor dele.

Apostamos nessa metodologia por acreditar que podemos construir inúmeros meios no ensino, de modo a pôr o aluno como o foco principal da aprendizagem, possibilitando sua protagonização, autonomia e criatividade deles, o que torna a educação uma área mais bonita.

\section{REFERÊNCIAS}

BRASIL. Ministério da Educação. Secretaria de Educação Básica. Base Nacional Comum Curricular - BNCC. Anos Iniciais. Ensino Fundamental. Brasília, DF, 2017. Disponível em: <http://basenacionalcomum.mec.gov.br/>. Acesso em: 16 set. 2020.

CERVO, A. L.; BERVIAN, P. A. Metodologia científica. São Paulo: Prentice Hall, 2002.

GIL, A. C. Métodos e técnicas de pesquisa social. São Paulo: Atlas, 1999.

MOURA, M. O. de. A atividade de ensino como unidade formadora. Bolema, Rio Claro, v. 12, p. 29-46, 1996.

MOURA, M. O. A atividade de ensino como ação formadora. In: CASTRO, A. D.; CARVALHO, A. M. P. de. (Org.). Ensinar a ensinar: didática para a escola fundamental e média. São Paulo: Pioneira Thompson, 2002.

MOURA, M. O. de, et al. Atividade Orientadora de Ensino: unidade entre ensino e aprendizagem. Rev. Diálogo Educ., Curitiba, v. 10, n. 29, p. 205-229, 2010.

VYGOTSKY, L. S. Formação Social da Mente. São Paulo: Martins Fontes. 6 ed. 2002. 
VYGOTSKY, L. S. Aprendizagem e Desenvolvimento Intelectual na Idade Escolar. In: LEONTIEV, A. et al. Psicologia e Pedagogia: Bases Psicológicas da Aprendizagem e do Desenvolvimento. Tradução: Rubens Eduardo Frias. São Paulo: Centauro, 2005. 